\title{
To Pin a SCFE One Screw is Preferred than Two Screws in Children
}

\author{
Udi Heru Nefihancoro
}

Department of Orthopedic and Traumatology, Dr. Moewardi Hospital/

Faculty of Medicine, Universitas Sebelas Maret, Indonesia

\section{ABSTRACT}

Background: Slipped capital femoral epiphysis (SCFE) is one of the most frequent hip disorders in children. SCFE is due to the displacement of the epiphysis (femoral head that keeps its location in the acetabulum) relative to the metaphysis (femoral neck) and shaft at the physic level. Treatment seeks to prevent worsening of epiphyseal slippage on the metaphysis, and percutaneous in situ fixation (ISF) using a single cannulated screw has long shown efficacy.

Case Presentation: An 11 years old boy presented with diagnosed with slipped capital femoral epiphysiolysis of right hip and treated operatively with one screw pinning guiding fluoroscopy. Post operatively, from X-Ray evaluation confirmed the proper position without joint penetration. Patient is then advised to walk with crutches for gradual weight bearing to full weight bearing after 4 weeks. Then after 6 weeks, patient had already walked normally again.

Conclusion: In unstable moderate-to-severe SCFE, the best reduction indications and technique remain controversial. There are many theories supporting one or two screws pinning technique. In this case we used one screw pinning fixation with excellent result.

Keywords: slipped capital femoral epiphysis, treatment, one screw in situ fixation

\section{Correspondence:}

Udi Heru Nefihancoro. Department of Orthopaedic and Traumatology, Dr. Moewardi Hospital/ Faculty of Medicine, Universitas Sebelas Maret, Jl. Ir. Sutami 36A, Surakarta, Central Java, Indonesia. Email:udyherunefy@ymail.com. Mobile: +62 816-672-767.

\section{Cite this as:}

Nefihancoro UH (2020). To Pin a SCFE One Screw is Preferred than Two Screws in Children. Indones J Med. 5(1): 24-30. https://doi.org/10.26911/theijmed.2020.05.01.04

cc) (i) (2) Indonesian Journal of Medicine is licensed under a Creative Commons

$$
\text { Attribution-NonCommercial-ShareAlike 4.0 International License. }
$$

\section{BACKGROUND}

Slipped capital femoral epiphysis (SCFE) is one of the most frequent hip disorders in children. SCFE is due to the displacement of the epiphysis (femoral head that keeps its location in the acetabulum) relative to the metaphysis (femoral neck) and shaft at the physic level (Witbreuk et al. 2013).

Most SCFE patients are younger than eighteen years old because proximal femoral physic fuses at the age of 18 in boys and 16 in girls. However, it can also appear in adults with a delayed skeletal maturation. Anything able to decrease the growth plate resistance or to maintain the epiphysis opened might result in SCFE at any age. The physiologic age when SCFE occurs is less variable than the chronologic age, which is called the narrow bone age window (Loder and Skopelja, 2011).

This suggests that SCFE only has the opportunity to appear while the physis is still opened, and this depends on the bone age (or bone health) more than on the chronological age. At cellular level, the physic in these cases shows loss of regular longitudinal cell column formation in the cartilage and increased intercellular matrix. The damage in SCFE occurs between hypertrophy zones and provisional ossification zones, 
although it can extend towards the germinal zone or into the metaphysis (Odgen and Southwick, 1977).

In cases of slippage of the capital femoral epiphysis (SCFE), gradual and progressive displacement of the epiphysis in relation to the neck occurs. This process is the result from shearing and compression forces on a diseased growth plate (Santili, 2001). This condition occurs mostly among overweight or even obese children at adolescent or pre-adolescent ages. There is a proportionally greater risk of being affected among patients undergoing hormone replacement or presenting endocrine diseases such as hypothyroidism or hypogonadism (Loder et al., 1995).

In the clinical evaluation, claudicating gait associated with groin pain that sometimes irradiates to the internal face of the thigh and/or the knee are symptoms that are often neglected at the first attendance, thus delaying the correct diagnosis. These insidious symptoms lead to non-definitive treatment for the disease and produce the erroneous idea that the use of symptoms, removal of the load, and traction of the limb followed by immobilization in a plaster cast or even simple observation would be enough to halt the progressive evolution of the slippage (Betz et al., 1990).

Treatment seeks to prevent worsening of epiphyseal slippage on the metaphysis, and percutaneous in situ fixation (ISF) using a single cannulated screw has long shown efficacy (Goodman et al., 1996). Residual deformity may nevertheless lead to femoroacetabular impingement or osteoarthritis of the hip in the medium-to-longterm (Hosalkar et al., 2012).

The present study reviewed SCFE patients managed by ISF at a minimum 10 years follow-up, to assess clinical and radiological outcome according to initial Southwick slip angle. The secondary objective was to determine a slip threshold as of which femoroacetabular impingement became more frequent after isolated ISF.

\section{CASE PRESENTATION}

An 11 years old boy presented with chief complain pain in the right hip. The child had history of fall from the stair one month ago. The childfelt pain when walking and now he could barely walk. Previously, the patient was an active child, could walk by himself without assistance, and slightly obese. X-ray was taken and the childwas diagnosed with slipped capital femoral epiphysiolysis of right hip and treated operatively with one screw pinning.

On a fluoroscopic table, the patient is supine and gentle transfer no reduction with a pad under the ipsilateral buttock and the lower limb entirely covered by the drapes. A lateral view can be obtained by moving the hip in flexion, abduction, and external rotation, Obtain good AP \& Lateral images, Draw Triangulation lines, lines overlying neck AP-L images (Figure 1).

In situ fixation is theoretically possible regardless of the extent of epiphyseal slippage. In practice, how-ever, screw placement is challenging and the risk of penetrating the joint cavity is increased when the slip angle is greater than $60^{\circ}$. The screw insertion site depends on the extent of the slippage. In early forms, the screw is inserted under the greater trochanter. When slippage is marked, the insertion site is on the anterior aspect of the femoral neck at the neck-shaft junction, and the distance between the insertion site and the growth plate decreases with the extent of slippage. 


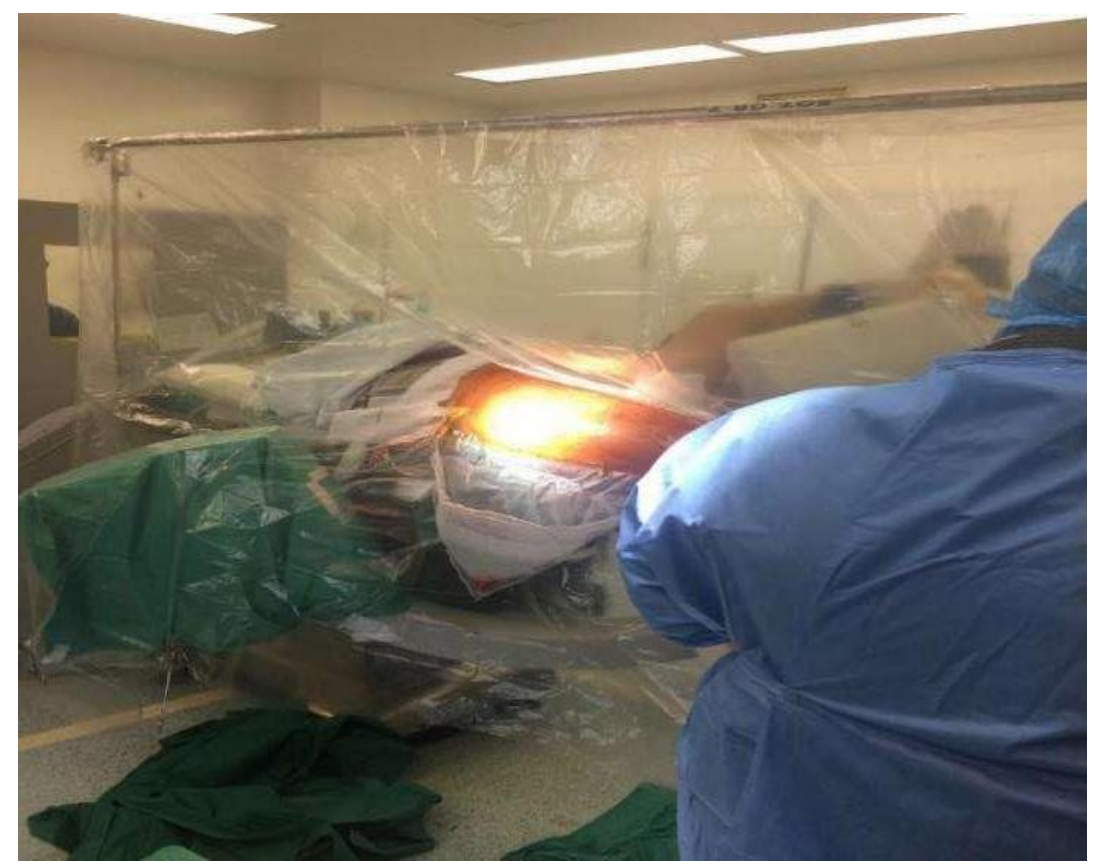

Figure 1. Supine on fracture table, gentle transfer no reduction. Move the C-arm not the lower extremity

A 1-cm incision is made in the skin for insertion of a threaded-tip guide wire (Figure 2), using a motorized wire driver. Advancement of the wire along the trajectory of the femoral neck is monitored on the image amplifier. The wire tip is positioned at the centre of the epiphysis. As the guide wire can be pushed forward by the bit and/or auger, a useful precaution consists in stopping guide wire advancement a few millimeters from the subchondral bone to avoid penetrating the joint cavity. A specific ancillary device is available for determining the optimal screw length.

The screw trajectory is prepared by drilling along the guide wire. Drilling is best stopped $5 \mathrm{~mm}$ from the guide wire tip to avoid guide wire backup upon withdrawal of the auger. The screw is inserted over the guide wire. 
Nefihancoro / SCFE One Screw is Preferred than Two Screws

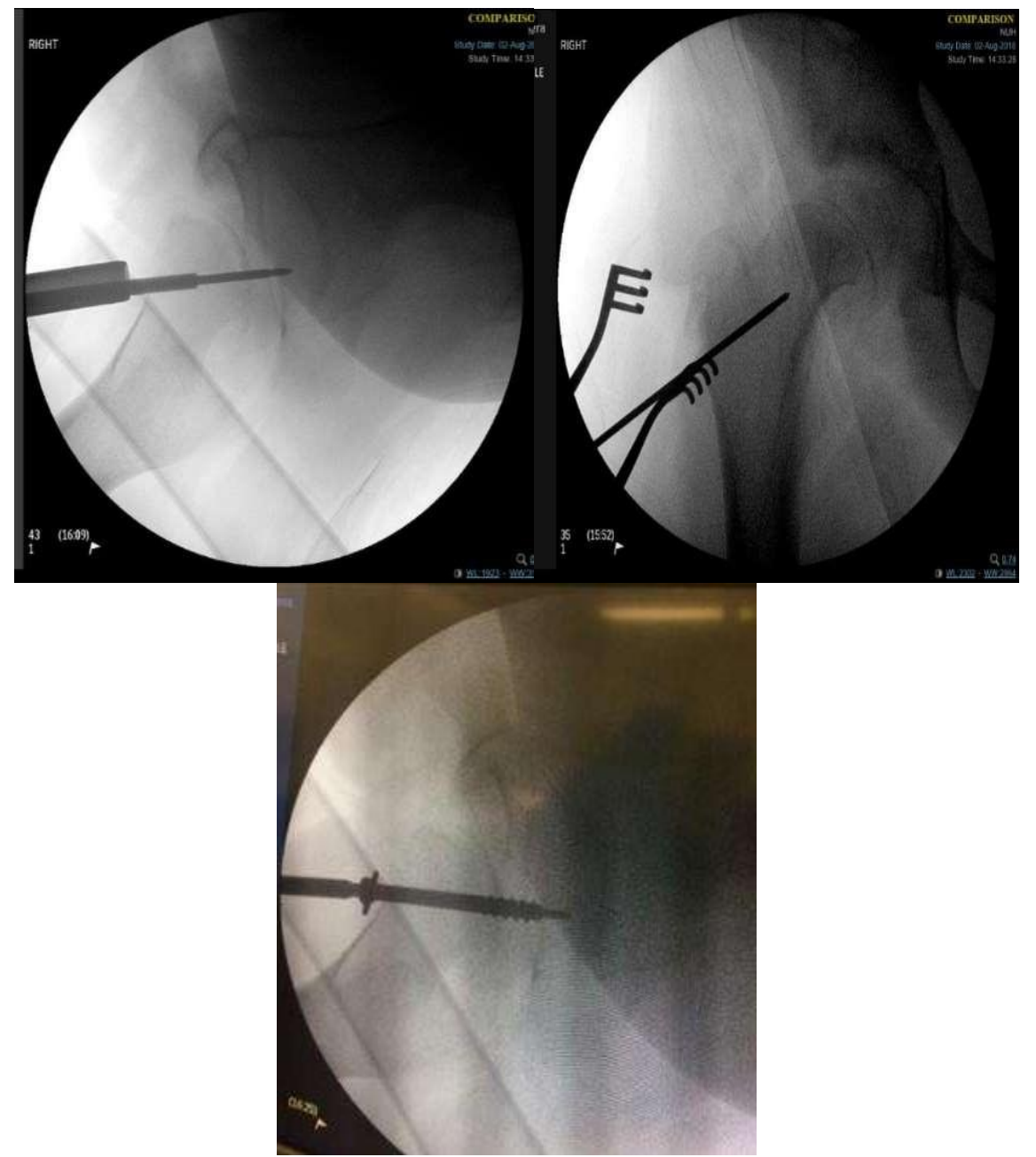

Figure 2. Insertion of Guide Pin 

The screw should be as central as possible to ensure optimal stability and to avoid focal epiphyseal necrosis.

Senthi et al. (2011) evaluated screw position after in situ fixation by comparing intra-operative radiographs to post-operative computed tomography (CT) images. The study concluded that screw tip location within $6 \mathrm{~mm}$ of the subchondral bone on the antero-posterior radiograph and within $4 \mathrm{~mm}$ on the lateral radiograph may result in penetration of the subchondral bone.

Several studies have established the efficacy of in situ fixation using a single screw (Carney et al., 2003). Use of a single screw can also be considered in unstable SCFE, although the risk of material breakage is higher (Mulgrew et al., 2011).

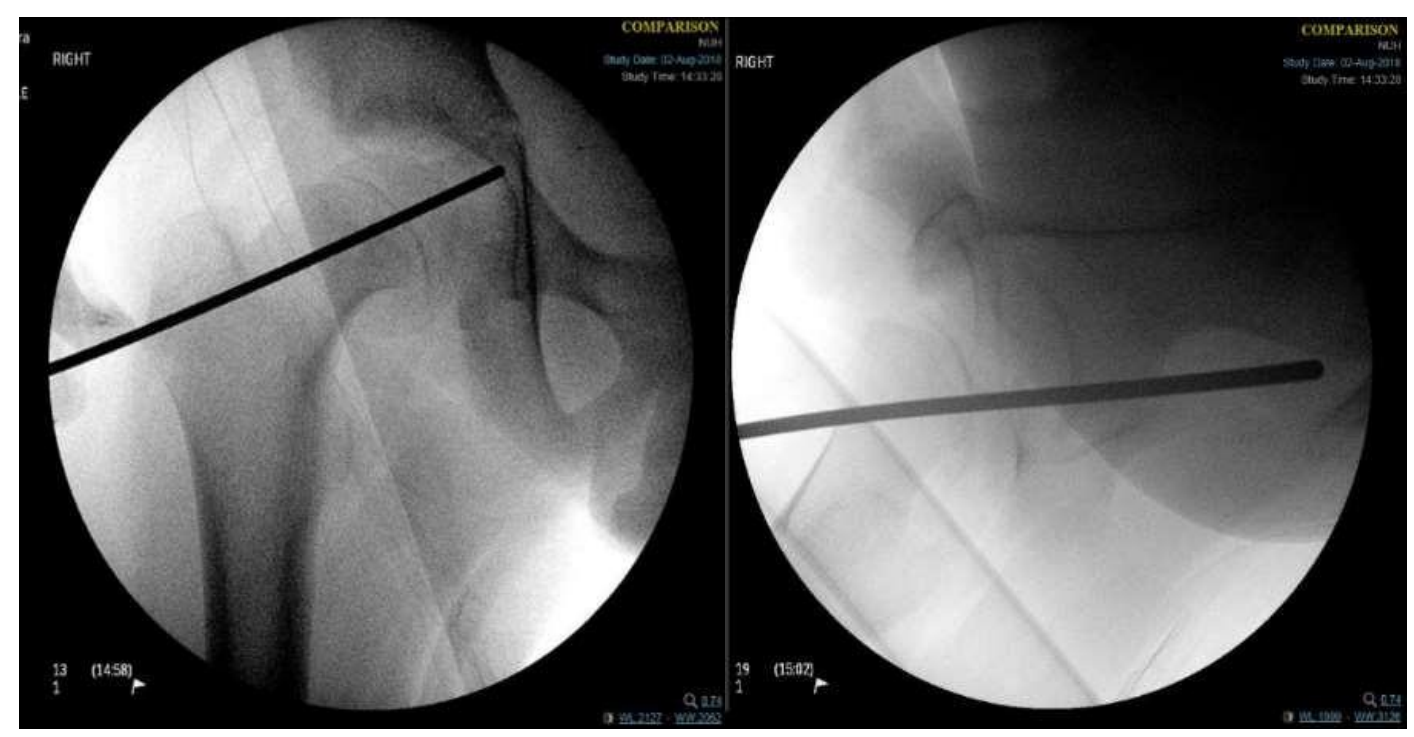

Figure 3. Placement of one screw start on the anterior neck and cross perpendicular to the physic.

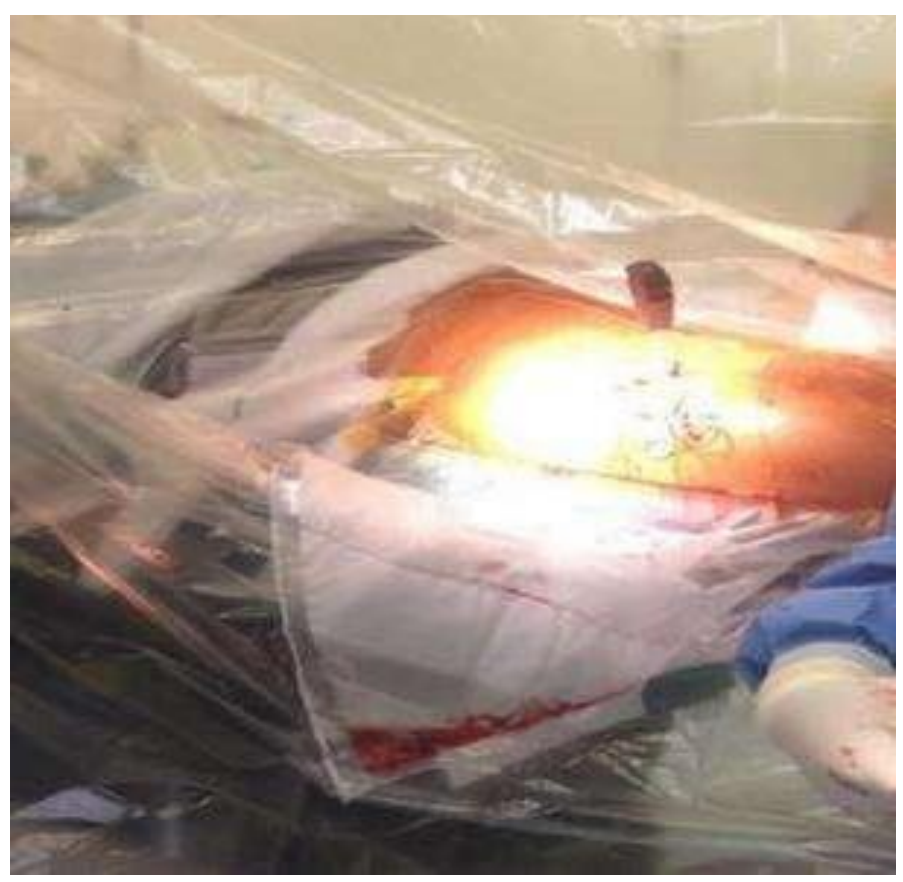

Figure 4. Placement of Screw ( $2 \mathrm{~cm}$ incision on the iliotibial band).

When the guide pins is appropriately placed (perpendicular to the physic\& center in both planes) 


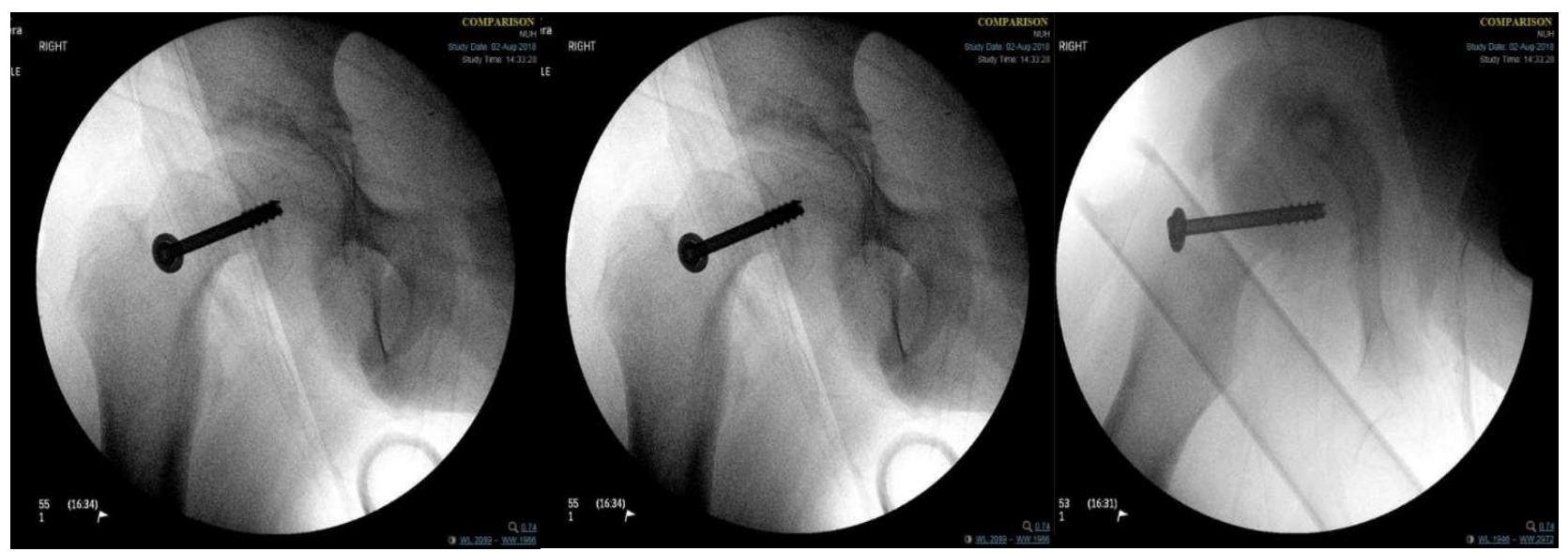

Figure 5. Placement of screw, confirmed the proper position without joint penetration

Post operatively, X-ray is taken (Figure 6) for evaluation. Patient is then advised to walk with crutches for gradual weight bearing to full weight bearing after 4 weeks. Then after 6 weeks, patient had already walked normally again.

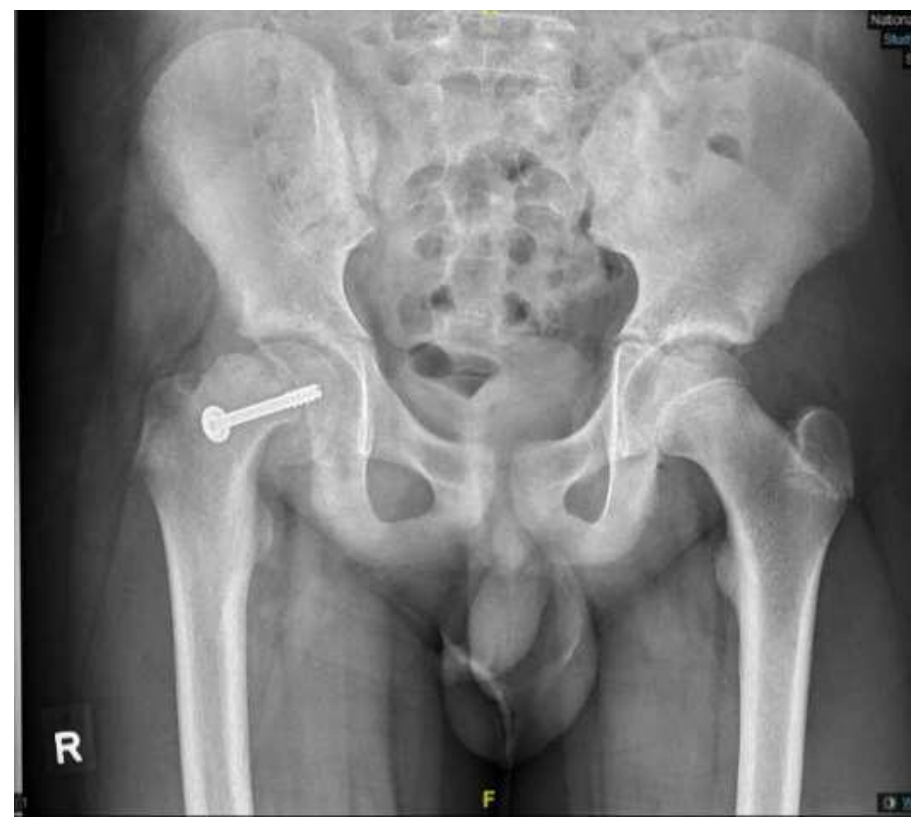

Figure 6. Final post op X-ray

\section{DISCUSSION}

On Mild - Moderate SCFE, in situ fixation can be done percutaneous using single screw with minimal scar and bleeding. Loder et al. (1995)stated that the benefit of in situ fixation with one screw is to reduce Soft Tissue Injury, avoid Slippage progresssion and decreased necrosis and chondrolysis.
Macía Villa et al. (2016) reported that 91\%-95\% success using technique in situ fixation with singe screw in Mild-Moderate SCFE cases and conservative treatmnet not recommended in this case. Abu-Amara et al. (2014) reported that complication of using more than one screw can penetrating joint cavity if Slip angle more than $60^{\circ}$. Santili et al. (2010) reported that effectiveness in situ fixation using single/double 
screw both in Stable or Unstable SCFE found no difference, slippage progression did not exceed $10^{\circ}$.

Kadowaki et al. (2017) reported that the risk of breaching the joint cavity increased in proportion to the number of pins. s. Several studies have established the efficacy of in situ fixation using a single screw. The use of a single screw can also be considered in unstable SCFE, although the risk of material breakage (in situ fixation). The screw insertion site is on the anterior aspect of the femoral neck the terminal branches of the medial femoral circumflex artery travel along the postero-superior aspect of the femoral neck and penetrate into the bone 2 to $4 \mathrm{~mm}$ from the bone-cartilage junction.

For the conclusion, SCFE is mainly a children's disease but it is also possible at older and atypical ages when physics are supposed to be closed. Although it is mandatory to rule out an underlying disease that can explain this lack of physiological consolidation, idiopathic cases prevail both in children and adults.

The primary treatment goal with all the available techniques is to prevent further slippage. In every case, the risk of iatrogenic avascular necrosis should be borne in mind. In mild forms, whether stable or unstable, in situ fixation is the reference standard. Fixation is achieved using cannulated pins or screws with various threading patterns.

In unstable moderate-to-severe SCFE, the best reduction indications and technique remain controversial. There are many theories supporting one or two screws pinning technique. In this case we used one screw pinning fixation with excellent result, although the risk of material breakage but minimal complication.

\section{AUTHOR CONTRIBUTION}

Udi Heru Nefihancoro diagnosed the patient, performed investigation, followed up, and drafted the manuscript.

\section{CONFLICT OF INTEREST}

The authors declare there is no conflict of interest in this study.

\section{FUNDING AND SPONSORSHIP}

This article did not receive any grants from any funding agencies.

\section{ACKNOWLEDGEMENT}

The Author is deeply grateful thanks to Prof. James Hui for support and sharing knowledge. The Author extends sincere thanks to Hanif W and David P Putra for their help.

\section{REFERENCE}

Abu-Amara S, Leroux J, Lechevallier J (2014). Surgery for slipped capital femoral epiphysis in adolescents. Orthopedics and Traumatology: Surgery and Research, 100(1S): S157-S167. https://doi.org/10.1016/j.otsr.2013.0 4.015

Betz R, Steel H, Emper W, Huss G, Clancy, M. (1990). Treatment of slipped capital femoral epiphysis. Spica-cast immobilization. Journal of Bone Joint Surgery, 72(4): 587-600. Retrieved from https://www.ncbi.nlm.nih.gov/pubmed/2324147

Carney B, Birnbaum P, Minter C (2003). Slip progression after in situ single screw fixation for stable slipped capital femoral epiphysis. Journal of Pediatric Orthopaedic, 23: 584-589. https://doi.org/10.1097/o0004694200309000-00004

Goodman W, Johnson J, Robertson JW. (1996). Single screw fixation for acute and acute-on-chronic slipped capital 
femoral epiphysis. Journal of Bone Joint Surgery, 74: 799-809. Retrieved from https://www.ncbi.nlm.nih.gov/pubmed/8542717

Hosalkar H, Pandya N, Bomar J, Wenger D. (2012). Hip impingement in slipped capital femoral epiphysis: A changing perspective. Journal of Children Orthopedic, 6: 161-172. https://dx.doi.org/10.1007\%2Fs11832-012-0397-z

Kadowaki S, Hori T, Matsumoto H, Kanda K, Ozeki M, Shirakami Y, FukaoT. (2017). Prepubertal onset of slipped capital femoral epiphysis associated with hypothyroidism: A case report and literature review. BMC Endocrine Disorders, 17(1): 1-5. https://doi.org/10.1186/s12902-017-0210-6

Loder R, Skopelja E. (2011). The Epidemiology and Demographics of Slipped Capital Femoral Epiphysis. ISRN Orthopaedic, 486512.https://doi.org/10.5402/2011/486512

Loder R, Wittenberg B, de Silva G (1995). Slipped capital femoral epiphysis associated with endocrine disorders. Journal of Pediatric Orthopaedic, 15(3): 349-356. https://doi.org/10.1097/01241398-199505000-00018

Macía Villa CC, Sanchez-Lite I, MedinaLuezas J (2016). Slipped capital femoral epiphysis in adults: Case report and review of literature. Reumatismo, 68(1): 40-47. https://doi.org/10.4081/reumatismo.2016.860

Mulgrew E, Wells-Cole S, Ali F, Joshy S, Siddique I, Zenios M (2011). Single screw fixation in stable and unstable slipped upper femoral epiphysis. Journal of Pediatric Orthopaedic, 20: 147-151.https://doi.org/10.1097/BPB.obo13e328344e76d

Odgen JA, Southwick W (1977). Endocrine Dysfunction and Slipped Capital Femoral Epiphysis. Yale Journal of Biology Molecular, 50: 1-16. Retrieved from https://www.ncbi.nlm.nih.gov/pmc/articles/PMC2595308/

Santili C (2001). Epifisiolise. RevistaBrasileira de Ortopedia, 36(3): 49-56.

Santili C,Akkari M, Waisberg G, Braga SR, Kasahara A, Perez MC (2010). Evolution of slipped capital femoral epiphysis after nonsurgical treatment. RevistaBrasileira de Ortopedia (English Edition), 45(5): 397-402. https://doi.org/10.1016/s2255-4971(15)30426-2

Senthi S, Blyth P, Metcalfe R, Stott N (2011). Screw placement after pinning of slipped capital femoral epiphysis: A prospective CT scan study. Journal of Pediatric Orthopaedic, 31: 388-392. https://doi.org/10.1097/BPO.obo13e$318217270 \mathrm{Od}$

Witbreuk M, Van Kemenade M, Van Der Sluijs J (2013). Slipped capital femoral epiphysis and its association with endocrine, metabolic and chronic diseases: A systematic review of the literature. Journal of Children Orthopaedic, 7: 213-223. https://doi.org/10.1007/s11832-013-0493-8 